\title{
SOBRE A ESTRUTURA DO DP: ALGUMAS CONSIDERAÇÕES ACERCA DA POSIÇÃO DO COMPLEMENTO NOMINAL EM RELAÇÃO AO NÚCLEO NOMINAL
}

\section{Adeilson Pinheiro Sedrins ${ }^{(*)}$ \\ Universidade Federal de Alagoas}

Resumo: Este trabalho retoma alguns estudos sobre a estrutura interna do Sintagma de Determinante, tomando como ponto de partida a ordem linear que complementos de núcleos nominais apresentam em relação a $\mathrm{N}$, em construções do Português Brasileiro. O objetivo é apresentar evidências da necessidade de projeção de categorias funcionais entre as projeções DP e NP, em função de oferecer explicações satisfatórias sobre a ordem em que constituintes do DP são realizados nessa língua.

Palavras-chave: Sintagma de determinante; complemento nominal; categoria funcional

\section{Introdução}

A hipótese DP de Abney (1987) ofereceu novas perspectivas para o estudo de sintagmas nominais, dentre as quais destacamos a postulação de atribuição de Caso genitivo para possessivos por uma categoria funcional - a saber, AGR - licenciada na posição nuclear D. Esse autor sugere que a categoria funcional D (em português representada pelos artigos, demonstrativos, etc.) subcategoriza o NP atuando sobre ele, construindo sua referencialidade e conferindo-lhe estatuto de argumento. A representação configuracional, em esquema $\mathrm{X}$-barra, do DP, segundo a hipótese de Abney é a seguinte.

(*) Mestrando do Programa de Pós-Graduação em Letras e Lingüística (PPGLL) e bolsista do CNPq. 
(1)

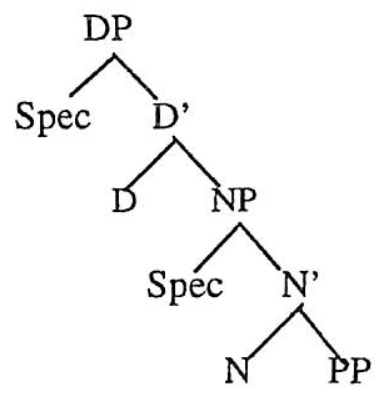

Essa configuração, em que o determinante toma como complemento (subcategoriza) o NP, apresenta vantagens teóricas, como, por exemplo, postular posições sintáticas distintas [Spec,DP] para determinantes e possuidores (os possuidores ocupariam a posição). ${ }^{1}$

Trabalhos subseqüentes à proposta de Abney, provenientes, principalmente, de estudos em diversas línguas, têm formulado projeções de categorias funcionais dentro do domínio do DP em detrimento, dentre outras coisas, de prover uma posição acima de NP para onde o movimento do núcleo nominal $\mathrm{N}$ seria licenciado, conforme veremos mais adiante.

De maneira geral, a partir da hipótese DP, os estudos sobre atribuição/ checagem de Caso (principalmente genitivo), sobre movimento de $\mathrm{N}$ para a projeção funcional dentro do $\mathrm{DP}$ em relação à ordem de adjetivos no DP, dentre outros, têm mostrado evidências empíricas tanto para a validação da proposta de Abney de uma projeção máxima para $\mathrm{D}$, quanto para a projeção de categorias funcionais entre DP e NP.

Neste trabalho discutimos em linhas gerais alguns estudos desenvolvidos dentro da perspectiva da teoria da gramática gerativa,

A estrutura comumente atribuída ao sintagma nominal era a representada em (i). Nessa representação, diferente da de Abney, D não projeta um nódulo XP:

(i)

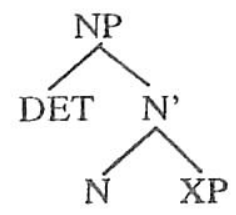


no que concerne à estrutura do sintagma de determinante (DP), em função da ordem em que o complemento nominal apresenta em relação a núcleos nominais $\mathrm{N}$, em construções do Português Brasileiro (PB). Conforme mostram os exemplos (2a) e (2b), a adjacência entre $\mathrm{O}$ núcleo nominal $\mathrm{N}$ e seu complemento pode ser "quebrada" por um adjetivo (2), não sendo possível a quebra por sintagmas preposicionais (PPs) correspondentes ao agente, quando introduzido pela preposição por (by-phrase), como mostra (3):

(2) a. O desmatamento desenfreado da mata atlântica pelos civis

b. A queima total de estoque

a. * O desmatamento pelos civis da mata atlântica

b. * A queima pelo gerente de estoque

Vemos, ainda, que, em algumas estruturas nas quais o núcleo nominal apresenta uma leitura resultativa, é mais produtiva a ordem "argumento externo" > "argumento interno" (complemento), quando ambos os argumentos são introduzidos pela preposição de (construções genitivas), conforme mostram os exemplos em (4):

a. A tradução de Raposo do livro de Chomsky

b. *A tradução do livro de Chomsky de Raposo

A partir dos contrastes verificados acima, este trabalho vem discutir algumas propostas que buscaram explicações para impossibilidades dos exemplos (3a), (3b) e (4b), bem como para a possibilidade dos exemplos em (2), e, embora nem todos os estudos tenham tomado para análise construções do $\mathrm{PB}$, veremos que uma comparação com construções de DPs de outras línguas como o inglês e o francês possibilitará verificar a validação para o PB de algumas generalizações desses trabalhos.

Seguimos uma ordem cronológica dos trabalhos com intuito de mostrar que com as mudanças no modo de pensar a estrutura do DP,
as explicações para as possibilidades/ impossibilidades dos exemplos (2)-(4), apresentam um maior poder descritivo/explicativo. Assim, iniciamos a próxima seção com o trabalho de Lobato (1990), baseado nas considerações de Chomsky (1986), anterior à hipótese DP de Abney (1987), no tratamento de construções semelhantes às apresentadas nos exemplos dessa seção, para verificar de que forma uma explicação para os fenômenos em questão seria possível de ser formulada. Em seguida, discutiremos propostas mais recentes em 
relação ao trabalho de Lobato que possibilitaram formular explicações mais plausíveis, em termos de descrição da estrutura do DP, para as possibilidades das construções apresentadas no início desta seção.

\section{A análise de Lobato (1990): parametrização entre $P B$ e francês para o Princípio de Adjacência de Caso}

O trabalho de Lobato (1990) trata de deslocamentos de constituintes dentro de DP com base nas considerações de Chomsky (1986) sobre a atribuição de Caso genitivo pelos núcleos $\mathrm{N}$ e $\mathrm{A}$, bem como sobre o Princípio de Adjacência do Caso (doravante, PAC), o qual diz respeito à possibilidade de a língua exigir sempre adjacência do atribuidor de Caso ou só exigi-la quando não ocorresse realização morfológica do Caso (cf. LOBATO, op. cit., p. 45).

A autora, comparando DPs do PB e do francês, verifica o seguinte contraste:

(5) a. A crítica de João ao livro.

b. * La critique de Jean du livre.

(6) a. A leitura / publicação/ tradução de João do livro.

b. * La lecture/ publication/traduction de Jean du livre.

a. A contestação/formulação/ apresentação de João da teoria.

b. * La contestation/ formulation/ présentation de Jean de la theórie.

(LOBATO, 1990, p. 35).

De acordo com Lobato, um recurso do francês para traduzir o significado das sentenças em (5b), (6b) e (7b) é a utilização de construções passivas que igualmente são possíveis em $\mathrm{PB}$, como mostram os exemplos que se seguem:

(8) a. A crítica do livro por João

b. La critique du livre par Jean

(9) a. A leitura/ publicação/ tradução do livro por João

b. La lecture/ publication/ traduction du livre par Jean.

(10) a. A contestação/ formulação/ apresentação da teoria por João

b. La contestation/ formulation/ présentation de la théorie par Jean

A impossibilidade dos exemplos do francês em (5)-(7), segundo Lobato, deve-se ao fato de os argumentos internos du livre e de la theórie serem introduzidos por preposição dummy - marcadora 
(e não atribuidora) de Caso, necessitando, conseqüentemente, de esses argumentos estarem em posição adjacente ao núcleo nominal atribuidor do Caso Genitivo.

A possibilidade de realização dos exemplos em (8b), (9b) e (10b) em francês deve-se ao fato de os argumentos internos, introduzidos pela preposição $d e$, estarem em posição adjacente a $\mathrm{N}$ e o agente (by-phrase) ser introduzido por preposição atribuidora de Caso (oblíquo) ao DP por ela subcategorizado, não havendo, por isso, nenhuma violação do PAC. De acordo ainda com Lobato, a possibilidade de realização dos exemplos em (5a), (6a) e (7a) no PB, em que haveria uma quebra do PAC, deve-se ao fato de o PB aplicar esse princípio apenas em estrutura profunda e o francês nas estruturas profunda e superficial.

Exemplos retirados de Laenzlinger (2005) de DPs do francês, no entanto, mostram a possibilidade da quebra de adjacência entre $\mathrm{N} \mathrm{e}$ seu complemento por um adjetivo, tal como acontece com o PB nos exemplos mostrados em (2). Verifiquemos então o exemplo em (11):

(11) la destruction recente de la ville

'a destruição recente da cidade'

(LAENZLINGER, 2005, p. 240 )

A possibilidade da construção em (11), invalida a assunção de Lobato acerca da aplicação do PAC também em estrutura superficial para o francês, apontando para o fato de que, na verdade, o que estaria em jogo no contraste observado nos exemplos (5)-(7) não seria uma restrição relacionada à aplicação desse princípio.

Nos exemplos de Lobato (1990), o que parece estar em jogo é uma diferença de leitura do nominal em processual ou resultativa. Ao contrário de nomes como destruição, que licenciam apenas uma leitura processual, os núcleos nominais dos exemplos de Lobato (crítica, publicação, tradução, apresentação) podem apresentar tanto uma leitura processual, quanto uma leitura resultativa.

Em português, por exemplo, o nome plantação pode designar o "ato de plantar", numa leitura de processo, como em (12a), ou uma leitura resultativa, referindo-se ao "produto" designado pela ação do verbo correspondente ao deverbal, como mostra (12b):

(12) a. A plantação de milho foi realizada pelos trabalhadores rurais.

b. A chuva acabou com a plantação de milho. 
Grimshaw (1990) analisando a estrutura argumental de deverbais apresenta testes para a identificação de uma leitura processual de nomes que também permitem leitura resultativa. Dentre esses testes estão: a) introdução do agente relacionado ao deverbal por por; b) modificação do deverbal por meio de adjetivos aspectuais como freqüente, constante e contínuo; c) o uso do artigo definido; d) adjetivo orientado para agente, como intencionall deliberado.

Aplicando, a seguir, os testes de Grimshaw a estruturas do PB, com nomes apresentados por Lobato, verificamos que a leitura processual só é possível para construções em que o agente é realizado em forma de by-phrase:

(13) a. A tradução contínua do livro por João

b. *A tradução contínua de João do livro.

(14) a. A freqüente publicação do livro por João

b. *A freqüiente publicação de João do livro

Os exemplos acima atestam a leitura processual dos nominais tradução e publicação, forçada pela presença dos adjetivos que bloqueiam os exemplos em (13b) e (14b).

Nos exemplos em (15), temos a leitura resultativa, devido, principalmente à natureza do verbo ler que bloqueia como complemento um DP com leitura processual. Note-se que, de acordo com Grimshaw, os resultativos, diferentemente dos processuais, que só permitem artigo definido, não fazem restrições a modificadores (determinantes, indefinidos, quantificadores):

(15) a. Li uma tradução de Raposo do livro de Chomsky

a'. ??Li uma tradução do livro de Chomsky por Raposo

b. Li toda a apresentação de Raposo do Programa Minimalista.

b'. ?Li toda a apresentação do Programa Minimalista por Raposo.

Um outro argumento contra a possibilidade da aplicação do PAC no francês, em estrutura superficial, são outros exemplos apontados por Laenzlinger (2005) para esta língua, em que é possível a ordem PPagente $>$ PPtema, porém, conforme observa, essa ordem é válida para DPs em que $\mathrm{N}$ não tem uma leitura de processo como em (16): 
(16) a. la description de Jean de l'événement

b. le portrait of Rembrandt of Aristote

c. la photo de Jean de la mer

Dessa forma, acreditamos que a impossibilidade dos exemplos (5)-(7) para o francês, apontados por Lobato, deva-se à leitura processual esperada pela lingüista quando, na realidade, seriam exemplos possíveis numa leitura resultativa e, para corroborar a leitura processual atribuída por Lobato aos exemplos (5)-(7), basta compararmos seu julgamento de gramaticalidade em relação aos exemplos (8)-(10), que são estruturas passivas, de leituras processuais.

\section{A estrutura do DP e o movimento de $\mathbf{N}$}

A relação entre os constituintes da sentença, na perspectiva da teoria da gramática gerativa, se dá de forma hierárquca. Dessa forma, podemos postular que os contrastes entre os exemplos apresentados em (2) - (4), conforme assumido em alguns trabalhos que se detiveram na estrutura de DPs ampliados por PPs, são decorrentes de diferentes posições que esses constituintes ocupam na estrutura interna do DP.

De maneira geral, assumindo a configuração X-barra para o DP apresentada, por exemplo, em Cinque (1994)e Giorgi \& Longobardi (1991), para o italiano; Cerqueira (1996) para o PB, o argumento externo do deverbal é gerado em [Spec, NP], conforme mostra a estrutura que segue:

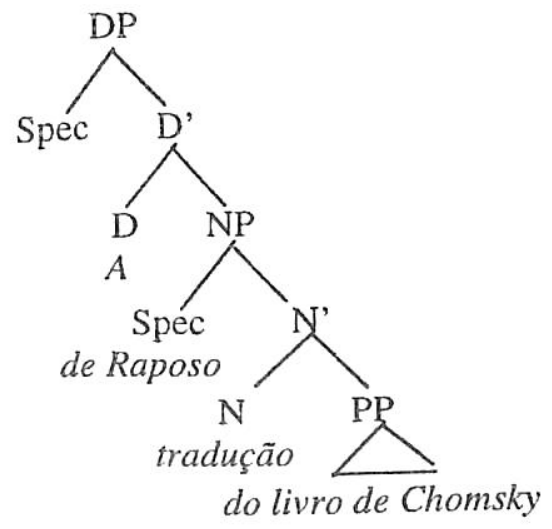


A ordem linear A tradução de Raposo do livro de Chomsky é resultante do movimento de $\mathrm{N}$ para uma posição nuclear de uma categoria funcional (FP) entre DP e NP:

(18)

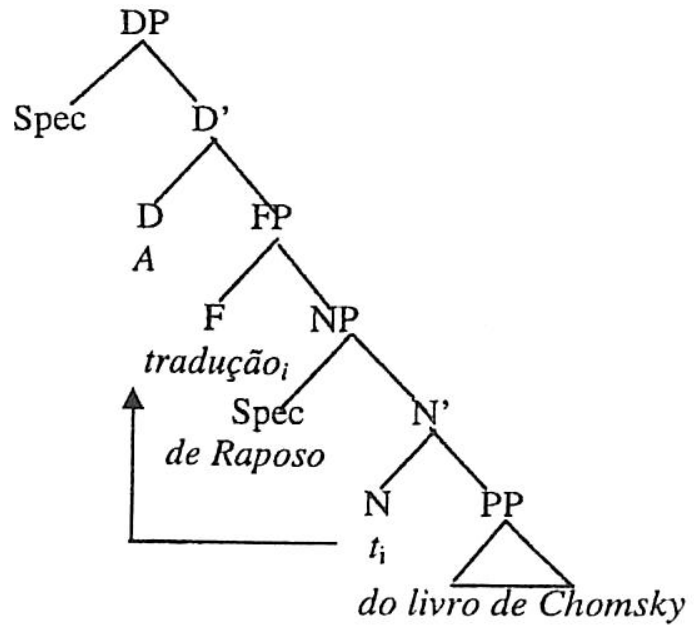

A postulação da projeção de uma categoria funcional entre DP e NP permite ainda explicar as derivações dos exemplos em (2), aqui retomados em (19), nos quais o adjetivo é realizado entre o núcleo nominal e seu complemento.

(19) a. O desmatamento desenfreado da mata atlântica pelos civis

b. A queima total de estoque

Construções como as acima apresentadas foram estudadas por Cinque (1994), que analisou o contraste de construções italianas como as que seguem ${ }^{2}$ :

(20) a. *l'italiana invasione dell"Albânia

b. l'invasione italiana dell'Albania

c. *l'invasione dell'Albania italiana

A partir da constatação da possibilidade de (19b), em que o adjetivo precede o complemento de $N$, contrapondo-se à impossibilidade da posposição do adjetivo ao complemento, bem

2 Ver também Giorgi \& Longobardi (1991). 
como à impossibilidade de este ocupar a posição pré-nominal, Cinque apresenta evidências de que a posição de base de sintagmas adjetivais (APs) em NPs tanto para línguas germânicas (em que o adjetivo precede o nome), quanto para línguas românicas (em que pode haver adjetivos pré e pós-nominais), é a mesma: à esquerda de $\mathrm{N}$.

O contraste em relação à posição do adjetivo em (21a), no francês, e em (21b), no inglês, deve-se ao fato de que para o francês e outras línguas românicas, como o português, é licenciado o movimento do núcleo nominal para um núcleo funcional intermediário (Y) entre $\mathrm{N}$ e D, conforme mostra (22):

(21) a. la voiture rouge

b. the red car

(22) movimento de N: [D...[AP Y [AP N]]]

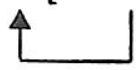

Assumimos então, seguindo a argumentação de Cinque, que as derivações dos exemplos em (19) do PB, são resultantes do movimento de $\mathrm{N}$ para o núcleo da projeção funcional, tal como acontece na derivação em que o "argumento externo" é projetado em [Spec, NP].

Em relação às construções nominais que apresentam o agente em forma de by-phrase, temos que a única leitura possível é a de processo, conforme mostram os exemplos que seguem, aos quais foram aplicados os testes apresentados por Grimshaw, de acordo com o que foi exposto na seção anterior. Lembremos que a presença de adjetivos como freqüiente só é possível em leitura processual do deverbal e que indefinidos são possíveis apenas para leituras resultativas.

a. O frequiente desmatamento da mata atlântica pelos civis

b. ?AIgum desmatamento da mata atlântica pelos civis

Para as construções passivas, em que o nome apresenta uma leitura processual, assumimos, com base nos trabalhos de Laenzlinger (2005) e de Cerqueira (1996), a estrutura que segue.

De acordo com Cerqueira (op. cit., p. 120), a posição em que o agente em forma de by-phrase é gerado é interna ao NP, ocupando a 
posição irmã de $N$, enquanto que o complemento de $\mathrm{N}$ é gerado em [Spec, NP]. As motivações de Cerqueira para essas assunções é a formulação de Larson (1988), seguindo ainda os trabalhos de Sportiche, 1990; Valois, 1991; Halle \& Keyser, 1995.

(24)

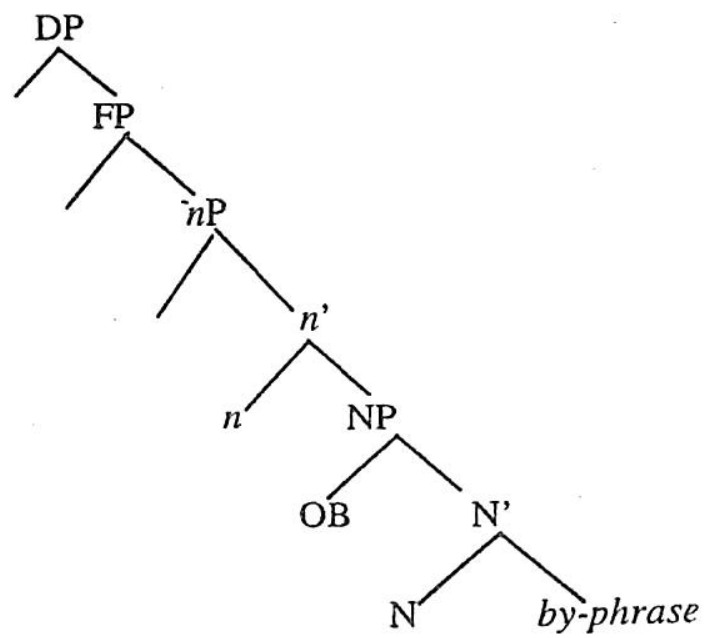

A ordem linear da construção exemplificada em (25), abaixo, é resultado do movimento de $\mathrm{N}$ para uma projeção funcional acima de NP, conforme mostra (26).

(25) a. O desmatamento da mata atlântica pelos civis<smiles>[18OH][Pb]</smiles>

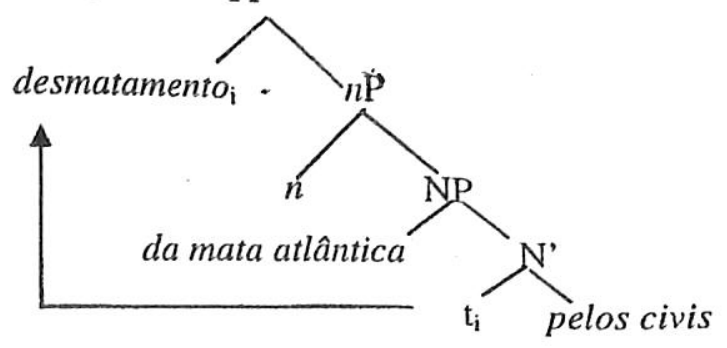

O fato de o agente da construção passiva ser gerado em posição mais baixa em relação ao complemento de $N$, explica a impossibilidade de essas construções serem realizadas entre $\mathrm{N}$ e seu 
complemento como mostrado nos exemplos em (3), retomados aqui em (27):

(27) a. * O desmatamento pelos civis da mata atlântica

b. * A queima pelo gerente de estoque

\section{Conclusão}

A possibilidade de considerar projeções de categorias funcionais entre os domínios de DP e NP, desencadeada a partir da proposta de Abney (1987), e a conseqüente tentativa de verificação de sua hipótese DP para outras línguas que não o inglês têm permitido ao modelo teórico da teoria gerativa oferecer explicações satisfatórias para fenômenos concernentes à parametrização entre as línguas em relação, por exemplo, à ordem dos constituintes no DP. A exemplo disso, temos o trabalho de Cinque (1994), mencionado anteriormente, que aponta evidência para movimento de $\mathrm{N}$ nas línguas românicas para um núcleo funcional, em contraposição às línguas germânicas.

Em relação ao trabalho de Lobato (1990), que previa uma parametrização da aplicação do Princípio de Adjacência do Caso (CHOMSKY, 1986) entre o PB e o francês, observamos, com base na possibilidade de em ambas as línguas haver movimento de $\mathrm{N}$, permitindo a realização de derivações com adjetivo entre $\mathrm{N}$ e seu complemento (CINQUE, op. cit.), que, na realidade, os contrastes verificados por essa autora entre o PB e o francês estão relacionados à leitura do deverbal como processo ou resultado.

Vimos que, de acordo com a leitura do deverbal, seguindo a abordagem de Grimshaw (1990), diferentes estruturas são projetadas em relação ao DP: Para deverbais com leitura resultativa, nos quais, conforme observado, a ordem mais produtiva é argumento externo > argumento interno, em que ambos são introduzidos pela preposição de, o argumento externo é projetado em [Spec, NP], e o argumento interno (complemento) projetado em posição adjacente a $\mathrm{N}$ e, com o movimento de $\mathrm{N}$ para uma projeção acima de NP obtém-se a ordem $\mathrm{N}$ $>$ argumento externo $>$ argumento interno.

Para deverbais com leituras de processo que apresentam estrutura passiva, assumindo análises baseadas em Larson (1988), como a de Cerqueira (1996) para o PB, o "objeto" de N é projetado em [Spec, NP] enquanto que o constituinte by-phrase é gerado em posição interna a $\mathrm{N}$, e, com o movimento de $\mathrm{N}$ para o núcleo de uma 
projeção funcional acima de NP, obtém-se em PB estruturas na ordem $\mathrm{N}>$ argumento interno $>$ by-phrase.

Restou-nos, no entanto, explorar as motivações do movimento de $\mathrm{N}$ para o núcleo de uma projeção funcional entre DP e NP. No entanto, considerar a possibilidade de movimento de $\mathrm{N}$ é plausível em virtude de que essa afirmação permite oferecer uma explicação para a ordem dos constituintes dentro de DP, conforme discutido no decorrer desse trabalho.

\section{Referências}

ABNEY, S. P. The English noun phrase in its sentential aspect, Ph.D. dissertation, MIT, Cambridge, Mass, 1987.

BELLETTI, A. (ed.). Structures and beyond: The cartography of Syntactic structures. Oxford University Press, Oxford-New York, 2004.

CERQUEIRA, V. C. A forma genitiva "dele" e a categoria de concordância (AGR) no português brasileiro. In: ROBERTS, I.; KATO, M. A. (orgs). Português brasileiro: uma viagem diacrônica. Campinas: UNICAMP, 1993.

CHOMSKY, N. O conhecimento da língua: sua natureza, origem e uso. Trad. Anabela Gonçalves e Ana Teresa Alves. Lisboa: Caminho, 1986 [1994].

CINQUE, G. On the evidence for partial N-movement in the Romance DP. In: CINQUE, G. et al. (eds.). Paths towards universal grammar. Studies in honor of Richard S. Kayne. Washington, DC: Georgetown University Press, 1994.

CINQUE, G. (ed.). Functional structure in the IP and DP. The cartography of syntactic structures. Oxford/New York: Oxford University Press, 2002. v. 1.

GIORGI, A.; LONGOBARDI, G. The syntax of noun phrases. Cambridge: Cambridge University Press, 1991.

GRIMSHAW, J. Argument structure. MIT Press, Cambridge, Mass, 1990. 
SOBRE A ESTRUTURA DO DP: ALGUMAS CONSIDERAÇŌES ACERCA DA POSIÇÃO DO COMPLEMENTO NOMINAL EM RELAÇÄO AO NÚCLEO NOMINAL

LAENZLINGER, C. Some notes on DP-internal movement. 2005. In: PUSKAS, G.; HAERBELI, E. (eds.). Generative Grammar in Geneva. 2005. Disponível em www.unige.ch/lettres/linge/syntaxe/journal/volume_quatre_2005.html. Acessado em 28 set 2005.

LOBATO. L. M. P. A questão dos deslocamentos dentro de sintagma nominal à luz do problema da aquisição de língua. In: CONGRESSO DA ASSOCIAÇÃO BRASILEIRA DE LINGÜÍSTICA, Rio de Janeiro, v. 10, 1990.

RIZZI, L. (ed.). The structure of $C P$ and IP: The cartography of syntactic structures. Oxford: Oxford U.P., 2004. 